\title{
Erratum
}

\section{Erratum: Caravagna, "Intricate Interplay between Innate Immune Cells and TRMP2 in a Mouse Model of Multiple Sclerosis"}

In the article "Intricate Interplay between Innate Immune Cells and TRMP2 in a Mouse Model of Multiple Sclerosis", by Céline Caravagna, which appeared on pages 2366-2368 of the March 27, 2019 issue, the article was published with the incorrect title. "TRMP2" should instead be "TRPM2". The correct title should read "Intricate Interplay between Innate Immune Cells and TRPM2 in a Mouse Model of Multiple Sclerosis". The authors regret this error. The online version has been corrected.

DOI: 10.1523/JNEUROSCI.1734-19.2019 